\title{
The facts and fiction of animal rights
}

The Speaking of Research website was founded by Tom Holder, who was an integral part of the UK-based organization Pro-Test and its first press officer. Pro-Test was begun by a 16-year-old high school dropout, Laurie Pycroft, who found himself in the midst of an animal rights demonstration at Oxford University, opposing the building of a new animal lab. Pycroft began his own protest group to support animal research. The movement, the history of which is chronicled on Speaking of Research's website, spread throughout the UK. It has been so successful in quelling animal rights activism there-along with serious help from UK laws that view animal rights attacks as acts of terrorism and enable dogged prosecution of perpetrators-that Pro-Test dissolved itself in the UK in 2011.

Speaking of Research is a source of information about animal rights group activities, now mostly in Europe. It also provides readers with the facts they need to counter most claims by animal rights groups that question the scientific validity of animal research.

The site presents up-to-the-minute news stories: two on animal rights extremists in Italy, which is a large and growing story; another about an animal extremist and his supporters in the UK; and one on attitudes toward animal research in Canada. But not all is about animal extremism and public attitudes: for example, there is a good review of animal research news from 2013. There is also a request for scientists to explain their research for Speaking of Researcha column called 'Speaking of Your Research.'

The 'Top Posts' section of the site leads to some educational materials about animal research: a bingo game, an article about a particularly visible animal rights activist, a quiz about a fictional research study, a debunking of some 'statistics' about animal use in drug testing, responses to the US Institute of Medicine's meetings on use of chimpanzees in research, information on use of zebra fish in research and several other informative pieces. This reviewer's favorite was on the morality and ethics of Gorgon aliens who invade our planet.

The 'About' section goes through the history of the website and of Pro-Test and provides biographical information about Holder, short biographies of members of the Speaking of Research Committee and information on commenting on web posts.

The 'Facts' section begins with information about 'The Animal Model.' Here, the use of animal models is explained, followed by a clickable list of diseases or conditions and the animal species used for researching them. The 'Medical Benefits' subsection has a brief explanation of animal use, as well as links to a pamphlet published by the UK's Understanding Animal Research, the 'Policy \& Government Affairs' tab of the Federation of American Societies for Experimental Biology (FASEB) and an illustrated 'Timeline of Medical Advances

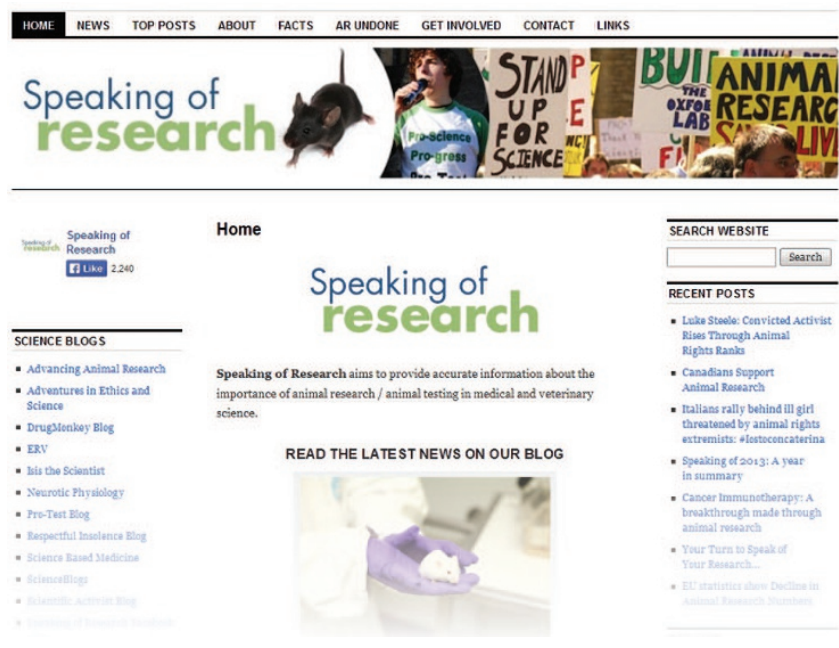

Made Possible by Animal Experiments', beginning in 1881 with the germ theory of infectious diseases and (inexplicably) ending in 2008. Other subsections include 'Veterinary Benefits', which describes how animal research benefits our pets, and a 'FAQ about Animal Research.'

The 'AR (Animal Rights) Undone' section begins with 19 myths commonly used by animal rights groups to illustrate why animal research is useless and incorrect and should be abandoned. The responses to these myths are authoritative, heavily referenced and, in some cases, linked to other websites and documents. One example is the claim that "blood transfusions were delayed 200 years by animal studies." This claim is quickly kicked to the curb with the explanation, "The idea that blood transfusions could have been successfully performed 200 years previously is nonsense, the necessary knowledge of the immune system and technological capability was just not there in the early 18th century." The debunking goes on to link to AnimalResearch.Info, which gives a history of blood transfusion.

Another section on 'Animal Rights Beliefs' leads to a short discussion on ethical questions related to animal research. There's also a subsection on 'Animal Rights Extremism' that explains and defines the terms and advises researchers about what to do if they have been targeted by animal rights extremists.

This is an excellent, informative site: much less informative about current animal research than about past animal research and extremely informative about animal rights activities. It's a must read for any animal researcher.

\section{http://www.speakingofresearch.com}
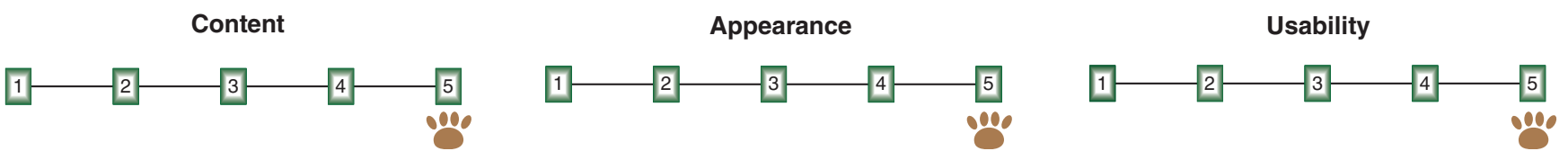